\title{
Remembering emotional events
}

\author{
ALAFAIR BURKE, FRIDERIKE HEUER, and DANIEL REISBERG \\ Reed College, Portland, Oregon
}

\begin{abstract}
Recent experiments have implied that emotional arousal causes a narrowing of attention and, therefore, impoverished memory encoding. In contrast, other studies have found that emotional arousal enhances memory for all aspects of an event. We report two experiments investigating whether these differing results are due to the different retention intervals employed in past studies or to their different categorization schemes for the to-be-remembered material. Our results indicate a small role for retention interval in moderating emotion's effects on memory. However, emotion had markedly different impacts on different types of material: Emotion improved memory for gist and basic-level visual information and for plot-irrelevant details associated, both temporally and spatially, with the event's center. In contrast, emotion undermined memory for de. tails not associated with the event's center. The mechanisms for emotion's effects are discussed.
\end{abstract}

The emotional events in one's life tend to be remembered with great clarity and detail (e.g., Bohannon, 1988; Brown \& Kulik, 1977; Christianson \& Loftus, 1990; Pillemer, 1984; Reisberg, Heuer, McLean, \& O'Shaughnessy, 1988; Rubin \& Kozin, 1984; White, 1989). But how accurate are these memories? There are a number of cases in which conspicuous errors have been documented in the recall of emotional events, despite the great vividness and high confidence attached to these memories (Christianson, 1989; Linton, 1975, pp. 386-387; McCloskey, Wible, \& Cohen, 1988; Neisser, 1982; Neisser \& Harsch, 1990; Wagenaar \& Groeneweg, 1990). Apparently, neither emotionality nor vividness provides any guarantee of memory accuracy.

In fact, there is reason to believe that emotional events may be remembered less completely than neutral events. According to the Easterbrook hypothesis, physiological arousal leads to a "narrowing" of attention-that is, a reduction in the range of cues to which an organism is sensitive (e.g., Bruner, Matter, \& Papanek, 1955; Easterbrook, 1959; Eysenck, 1982; Mandler, 1975). Since arousal generally accompanies emotion, emotion should also lead to this narrowing of attention. This should in turn lead to impoverished memories, since the "center" of the event might be well remembered, but little else will be. If, therefore, many details are subsequently recalled, these are likely to be after-the-fact reconstructions and, thus, open to error.

A number of studies have examined these claims, but with conflicting results. Much of the research has examined memory for specific details about emotional events (color of clothing, details of background, etc.). It is

This research was supported by funds from the Pew Charitable Trust and from Reed College. We thank Ben Harper for his help in completing Experiment 1, and Audrey Wessler for her help in completing Experiment 2. Requests for reprints should be sent to the third author at Psychology Department, Reed College, Portland OR 97202 (e-mail: reisberg@reed.edu). presumably just these details that might be excluded by the hypothesized narrowing of attention. These specific details about an episode also cannot be reconstructed from more generic knowledge, making these details a good index of memory per se. Finally, it is precisely the abundance of these details that seems to characterize the "vividness" with which emotional events are recalled.

Many studies have found that arousa ${ }^{1}$ has an adverse effect on memory for detail (e.g., Clifford \& Hollin, 1981; Clifford \& Scott, 1978; Deffenbacher, 1983; Loftus \& Burns, 1982; Siegel \& Loftus, 1978; for a review, see Heuer \& Reisberg, in press). For example, Loftus and Burns (1982) showed subjects a brief film clip depicting a bank robbery. For half of the subjects, the film showed the robber run out of the bank with two men pursuing him. The robber then turned and shot a small boy in the face. For the remaining subjects, the film was the same until the shooting, but then cut back to the inside of the bank, where the manager was telling everyone to remain calm. Immediately after viewing the film, subjects' memories were tested for the early part of the film (i.e., the portion of the film identical for the two groups). Subjects who had seen the neutral version remembered more detail, a finding that emerged both with recognition and recall testing.

In contrast, at least a few studies have found that arousal benefits memory for detail (e.g., Andrews, 1990; Dorman, 1989; Heuer \& Reisberg, 1990). For example, Heuer and Reisberg (1990) showed subjects a series of slides depicting a story. In the neutral version of the story, a mother takes her son to visit his father at work. The father is a mechanic, and the son watches the father repair a car. The arousal version of the slides was identical to the neutral version except for the middle of the sequence; the father in the arousal version is a surgeon, and the son watches as the father performs surgery.

Subjects viewed one of these stories, then, two weeks later, completed both a recall test and a four-alternative forced-choice (4AFC) recognition test. In both tests, mem- 
ory was assessed for central and for peripheral information. Central information was defined as any fact or element pertaining to the basic story that could not be "changed or excluded without changing the basic story line." This categorization relied on a basic-level description of the episode depicted in the slides (Rosch, 1978; see also Morris \& Murphy, 1990; Rifkin, 1985; Vallacher \& Wegner, 1987). An example of central information was the fact that the father was a surgeon and not a pediatrician. An example of peripheral information was the color of the mother's sweater. Heuer and Reisberg found that subjects who viewed the arousing sequence remembered more of both central and peripheral information than did those who viewed the neutral sequence.

Thus, there is a conflict in the available evidence. The Heuer and Reisberg result (and others cited above) seems to contradict that obtained by Loftus and Burns (and others), showing that arousal undermines memory. We note that the latter finding is by far more common in the literature, and, indeed, the studies showing beneficial effects of arousal are largely from a single laboratory (our own). We therefore need to be cautious in interpreting these results. Nonetheless, our studies have been consistent in showing an arousal advantage for detail memory, and we have observed this effect with a variety of procedures and a variety of story materials. Thus, we need to ask why these findings are at odds with other results in the literature.

Unfortunately, our understanding of this data pattern is hindered by the diversity of procedures and stimuli employed throughout this literature. For example, the studies already described have employed different stimuli, different memory tests, different instructions, and different retention intervals; at present, we have litcle information about how these factors influence arousal's memory effects. What therefore seems called for is a systematic examination of these factors, in order to map how these shape the data.

The present article reports two such "parametric" studies, examining the (potential) interaction among arousal, retention interval, and type of to-be-remembered material. In addition, we report data on the impact of repeated memory testing for emotionally arousing events (i.e., withinsubject comparisons of immediate and delayed test). Before turning to the studies, though, we summarize the considerations that led us to focus on these factors.

Most of the studies showing negative effects of arousal (that is, better memory by the control subjects) have employed short retention intervals. For example, Christianson (1984), Christianson and Loftus (1991), Clifford and Hollin (1981), Clifford and Scott (1978), Deffenbacher (1983), Kebeck and Lohaus (1986), Loftus and Burns (1982) and Siegel and Loftus (1978) all report evidence that emotional arousal undermines memory accuracy, and all employed retention intervals under $1 \mathrm{~h}$. In contrast, a number of authors have employed retention intervals of 2 weeks or longer, and they report that arousal improves memory for detail (Andrews, 1990, Studies 1 and 2;
Christianson, 1984; Dorman, 1989; Heuer \& Reisberg, 1990; Snyder, 1989).

We need to be cautious, however, about drawing conclusions from this pattern across diverse studies. Fortunately, a few studies have directly examined the interaction between emotional arousal and retention interval. Unfortunately, the relevant results are difficult to interpret. For example, Kleinsmith and Kaplan (1963, 1964) found that memory for emotional words was poorer than for neutral words when subjects were tested immediately; after a 1-week delay, this pattern reversed, and retention was better for emotional material. (For reviews of related studies, see Craik \& Blankstein, 1975; Eysenck, 1976; Hockey, 1978.) However, it is unclear how to apply these findings to questions of detail memory, since the to-beremembered materials in these early studies consisted of simple word lists, quite unlike the complex stimuli employed by Loftus and Burns or by Heuer and Reisberg.

A small number of studies, though, have examined the relation between arousal, retention interval, and memory for complex events. Christianson (1984) had subjects view either a neutral or an arousing story depicted in a slide sequence. ${ }^{2}$ Memory was tested either $12 \mathrm{~min}$ after the presentation or after 2 weeks. Half of the subjects were asked to recall the main content of the slides they had seen; the others were given a recognition test, with the distractors differing from the originally presented slides only in camera angle. (Hence, correct choices depended on memory for various details about the layout of the slide-exactly what was visible, what was occluded, and so on.) With a short retention interval, subjects who viewed the neutral slide sequence performed better in this recognition test than did those who viewed the arousing slides. With a long retention interval, this pattern reversed. A similar interaction between story type and retention interval (but without the crossover) appeared in the recall data.

Christianson's data indicate that retention interval is an important variable in assessing arousal's effects on memory. However, a more recent study failed to replicate this arousal $x$ interval interaction: Christianson and Loftus (1987) employed the same stimuli and retention intervals as those used in Christianson's earlier study, but they found that arousal undermined detail memory (again, for camera angle) in both the immediate and the delayed tests. These contrasting data patterns are possibly due to the different instructions given to subjects in these two studies, but this suggestion stands merely as a conjecture about this apparent data conflict.

The role of retention interval was also examined by Kebeck and Lohaus (1986). In their procedure, subjects were shown either an arousing version of a film or a neutral version; memory was tested immediately after the film and then again 2 weeks later. The data indicate no arousal effect on memory for gist; however, subjects who viewed the arousing version of the film showed poorer memory for peripheral detail in both the immediate and the delayed test. These findings indicate that arousal's effects are not influenced by retention interval, contrary to the Chris- 
tianson (1984) and the Kleinsmith and Kaplan (1963, 1964) findings. However, it is hard to know if the delayed test in Kebeck and Lohaus's study was influenced by the earlier experience of the immediate testing. That is, subjects' own recall in the immediate test could have functioned as postevent information, which is known to influence subsequent memory performance (Loftus, 1979). Indeed, the literature contains several reports of subjects' early recall contaminating later recall (Bartlett, 1932; Belbin, 1950). This makes the Kebeck and Lohaus findings difficult to interpret.

These studies leave unresolved the issue of how retention interval moderates arousal's effects on memory and also raise a question about what role might be played by repeated testing. As mentioned earlier, the importance of retention interval is clearly suggested by various studies showing negative effects of emotional arousal at short delays and the studies showing positive effects at long delays. However, we are apprehensive about these comparisons across studies, largely because the to-be-remembered materials are so different. This brings us to the second main focus of the present experiments.

The Easterbrook hypothesis (described earlier) leads to the claim that attention will be narrowed during emotional events, so that some aspects of the event will be excluded from attention and so poorly remembered later on. Other aspects of the event will be attended and so, perhaps, better remembered. Thus, the hypothesis predicts that emotion's effects will be uneven, clearly interacting with type, or perhaps location, of the to-be-remembered material. A similar claim derives from the phenomenon of weapon focus, an effect alleged for witnesses to violent crimes, in which the witness's attention is caught by the weapon, to the exclusion of much else. (Heuer \& Reisberg, in press, provide a review of the weapon-focus literature.) The weapon-focus claim, like the Easterbrook hypothesis, posits a narrowing of attention in emotional situations, and so, once again, leads to the expectation of emotion having uneven effects on the to-be-remembered material.

A number of researchers have sought to test these claims by categorizing the to-be-remembered material into central and peripheral information and asking how these are individually influenced by emotion. Unfortunately, these categories have been defined in various ways in the literature, making it difficult to pool the evidence. For example, Heuer and Reisberg (1990) used a distinction between plot-relevant and plot-irrelevant materials in distinguishing central and peripheral information; they found that arousal improved memory for both of these categories of information. In contrast, Christianson and Loftus (1991) report that arousal improved memory for central materials, but at the cost of memory for peripheral information. However, in their study, detail that was merely "associated with" central characters in the plot (e.g., the color of the central character's coat) was defined as central, even if this detail was plot irrelevant. Thus, Heuer and Reisberg employed a conceptual distinction to identify peripheral information; Christianson and Loftus em- ployed a perceptual/spatial distinction. These categorization schemes often overlap, since, in filmed events, plot-relevant material is often visually central. Nonetheless, the difference in definitions makes interpretation of the evidence difficult.

These variations in definitions, and in the to-beremembered materials, draw attention to an important problem: If emotion has different effects on different types of information, these will go undetected unless we partition the to-be-remembered material appropriately. The problem, of course, is that we do not know which partition is the correct one. At least for now, therefore, it seems appropriate to let our investigations of emotion's impact be data driven and to treat the type of the to-be-remembered material as a parameter to be systematically varied. It is this approach that we have taken in the present studies.

We therefore report two experiments exploring these various issues. The experiments differ in several details, but both have the same outline: One group of subjects viewed a series of slides depicting an emotionally arousing story; one group viewed a series of slides depicting a neutral (but otherwise comparable) story. Within each group, some subjects were tested immediately, and others at a delay. Memory was probed for four different types of material (described below), thus treating type of tobe-remembered material as a variable to be systematically assessed. Finally, the data were subdivided according to phase of the story: an initial phase (prior to the arousal manipulation), a second phase in which the arousal manipulation took place, and a final phase (identical for the two groups). This allowed us to examine possible proactive and retroactive effects of emotion on memory. Thus, overall, both studies have multifactorial designs, with factors of story type, retention interval, type of tobe-remembered material, and story phase.

The two experiments reported here are similar in many ways. Therefore, we first describe each study's design and methods, then we present the results in a single, combined Results section. ${ }^{3}$

\section{EXPERIMENT 1}

In Experiment 1, we explored two issues relevant to emotion's effects on memory. First, we examined the claim that emotion's effects on memory depend largely on retention interval. To this end, we replicated the Christianson (1984) design, but with new stimuli and new tobe-remembered materials. As discussed above, this replication seems critical, given the seeming conflict between Christianson's results and those of Christianson and Loftus (1987). The experimental comparison here is straightforward: Half of our subjects viewed emotional materials, and half viewed neutral materials. Within each group, some subjects were tested immediately after the story presentation, others were tested after a 1-week delay, and still others were tested after a 2-week delay.

Second, the present study was designed to examine how emotion influences memory for different types of to-be- 
remembered material. To this end, we recategorized the test items used by Heuer and Reisberg (1990) into four types of information: Heuer and Reisberg's central information (i.e., plot relevant or plot defining) was subdivided into gist and basic-level visual information; their peripheral category (i.e., plot-irrelevant material) was subdivided into central details and background details. (This subcategorization builds on the spatial distinction proposed by Christianson \& Loftus, 1991. Details of our entire categorization scheme appear below.)

\section{Method}

Subjects. Seventy-two volunteers participated as subjects, recruited from two liberal-arts campuses in the Portland area. 4 To subjects failed to appear for the second experimental session; their data were removed and these subjects were replaced. The subjects were randomly assigned to groups, with the provision that each group contain approximately equal numbers of male and female subjects.

Materials and Apparatus. The stimuli were identical to those employed by Heuer and Reisberg (1990). They consisted of 12 slides, each accompanied by a tape-recorded sentence of narration. The slides were projected onto a rear-projection screen at a size of $20 \times 14$ in. The subjects were seated about 31 in. from the screen. Each slide was shown for $6 \mathrm{sec}$, with a 1-sec interstimulus interval. The taped sentences were heard from a speaker placed behind the screen. Each sentence began approximately $500 \mathrm{msec}$ after the appropriate slide was projected and lasted approximately $4 \mathrm{sec}$.

The first three slides and the final four were identical for the two groups. In Slides 1-4 (Phase 1), a mother and son are going to visit father at work. Slide 4 shows the father's workplace-the outside of a hospital for the arousal group, the outside of a garage for the neutral group. In the third phase, Slides 9-12, the mother leaves the father's workplace, makes a telephone call to her boss, and hails a cab. The arousal manipulation occurred in Phase 2, Slides 5-8. In the neutral slides, the father is a mechanic who is repairing a car. For the arousal group, the father is a surgeon who is operating on a victim of a car accident. The arousing slides depict a team of surgeons bending over a patient whose internal organs are plainly visible (Slide 6), the injured legs of a child (Slide 7), and the father removing his surgical gloves (Slide 8). For both groups, there were 11 color and 1 black-and-white slide. (This variation was included as a detail for which memory could be assessed; the black-andwhite slide was in the eighth position in the sequence, i.e., in the second phase.)

As mentioned, seven of the slides were identical for the two groups. The five differing slides were matched as closely as possible for content and visual form. For example, Slide 6 for the neutral version showed a group of mechanics huddling over an automobile, with its engine plainly visible. The number and position of the mechanics, camera angle, and so on were approximately matched to those of the arousal group's Slide 6. Likewise, Slide 7 for the neutral version showed a broken automobile part, with its layout and background matched to that of Slide 7 for the arousal group. Finally, the sentences of narration for each slide were also matched for length and form. (The specific sentences are listed in Heuer \& Reisberg, 1990.)

To assess subjects' level of physiological arousal, heart rate was monitored by a CIC heart rate speedometer, with a photosensitive cell attached to the subject's earlobe. The monitor gave a digital output that was recorded by the experimenter for baseline rates and for changes during the slide presentation. In order to keep subjects steady, their heads were stabilized in chinrests. The equipment and the experimenter were hidden behind the projection screen during the procedure to minimize distraction.

Memory for the slide material was assessed with a recognition test, containing 119 questions (10 per slide, with 1 removed be- cause of ambiguity). All of the questions were in 4AFC format, with the position of the target counterbalanced among the four alternatives. The questions themselves had been categorized earlier into four types. Two of the categories subdivided the materials Hever and Reisberg had classified as central, and two divided their peripheral category. The categorization of items was done by the first two authors. Even with independent judgments, there was a 95\% level of agreement. (Disputes were settled by the third author.)

The following criteria were used in the categorization of the questions: (1) Any fact or element that one would include when narrating the story of the slide material was considered to be gist (e.g., that father is the chief surgeon and not a pediatrician). Items in this category were roughly the basic-level answers to the question, "What happened next?" No items pertaining to the visual presentation of the material were included in this category. (2) Basic-level visual information included any element one would mention when describing what the slide showed-essentially a basic-level answer to the question, "What does this slide show?" For example, that a slide showed mother hailing a cab, and not walking, would be in this category. (3) Central detail included peripheral (plot-irrelevant) information associated with the central figures in the story (e.g., the color of the mother's sweater, given that mother was centrally depicted in the slide). (4) Finally, any detail not concerned with the central characters was considered background detail (e.g., whether a slide centrally depicting a broken car also contained other cars in the background).

Table 1 provides examples of the questions in each category. For Phases 1 and 3, identical questions were asked of the neutral and arousal subjects. For Phase 2, every effort was made to match the questions asked of the two groups, although this was more difficult for gist and for basic-level visual information than for the other categories of information. Even in Phase 2, however, many of the questions asked of the arousal subjects were identical to those asked of the neutral subjects (e.g., the colors of central objects in the slide, or the time of day at which an event took place, or whether a slide depicted both mother and child, or either, or bystanders, or no people).

The test questions were presented to all subjects in the same sequence; this was because many of the questions presupposed answers to earlier questions (e.g., a question might ask whether the mother was visible in a particular slide; a subsequent question might ask what the mother was carrying). Within this constraint, the distribution of categories of questions was balanced as much as possible. That is, the four categories of test items were distributed across the memory test as evenly as possible.

Finally, as part of a separate experiment, the subjects also completed a brief (10-15 min) questionnaire before taking the memory test. The questionnaire assessed (by self-report) the length of time subjects tend to think about various events before and after they occur.

Design. Half of the subjects viewed the arousing slides, and half viewed the neutral slides. As indicated above, each of these slide sequences was divided into three phases, with the middle phase including the arousal manipulation. This division into phases was only for purposes of analysis; nothing marked the phases from the perspective of the subjects.

In order to examine the effects of retention interval, half of the subjects (i.e., 18 arousal subjects, 18 neutral subjects) were assigned to an immediate-test condition (10 to 15-min delay). The remaining subjects were assigned to the delayed-test condition. Within this latter group, half of the subjects (i.e., 9 arousal subjects, 9 neutral subjects) were tested after a 1-week delay, and half were tested after a 2-week delay.

Procedure. The subjects were tested individually, in two sessions. Because the memory test was to be incidental, the subjects were told at the outset that the purpose of the experiment was to measure "physiological arousal in reaction to various stimuli." The first session began with measurement of subjects' baseline heart rate. The subjects were seated (and given the instructions for the 
Table 1

Exampies of Test Items for Each Type of Information

\begin{tabular}{|c|c|c|c|}
\hline \multirow[b]{2}{*}{ Item Type } & \multicolumn{2}{|c|}{$\begin{array}{c}\text { Number of Test } \\
\text { Items }\end{array}$} & \multirow[b]{2}{*}{ Examples } \\
\hline & Neutral & Arousal & \\
\hline Gist & 25 & 25 & $\begin{array}{l}\text { Slide } 3 \text { : What are they [mother \& child] going to do? } \\
\text { a. nun errands } \\
\text { b. go to get the car } \\
\text { c. visit a relative } \\
\text { d. go to see the pediatrician }\end{array}$ \\
\hline \multirow[t]{2}{*}{$\begin{array}{l}\text { Basic-level } \\
\text { visual information }\end{array}$} & 14 & 15 & $\begin{array}{l}\text { Slide } 5 \text {, neutral: The people in the slide are } \\
\text { a. walking by } \\
\text { b. helping to hook up the towtruck } \\
\text { c. looking at the broken car } \\
\text { d. talking to a policeman }\end{array}$ \\
\hline & & & $\begin{array}{l}\text { Slide } 5 \text {, arousal: The people in the slide are } \\
\text { a. standing and staring at the accident } \\
\text { b. rushing towards the scene } \\
\text { c. helping to clear the debris lying around } \\
\text { d. being questioned by a policeman }\end{array}$ \\
\hline Central details & 29 & 31 & $\begin{array}{l}\text { Slide 11: Mother is leaning } \\
\text { a. On a ball } \\
\text { b. On the shelf under the phone } \\
\text { c. against the wall } \\
\text { d. on her purse }\end{array}$ \\
\hline \multirow[t]{2}{*}{ Background details } & 51 & 48 & $\begin{array}{l}\text { Slide } 6 \text {, neutral: In the background you can see } \\
\text { a. other cars in the garage } \\
\text { b. a toolbench } \\
\text { c. a hydraulic lift } \\
\text { d. none of these }\end{array}$ \\
\hline & & & $\begin{array}{l}\text { Slide } 6 \text {, arousal: In the background you can see } \\
\text { a. lamps } \\
\text { b. an I-V setup } \\
\text { c. a sink } \\
\text { d. none of these }\end{array}$ \\
\hline
\end{tabular}

Note-The correct answer is indicated by a bold-face letter.

procedure) for approximately $5 \mathrm{~min}$. Heart rate was then measured for a period of $30 \mathrm{sec}$. The lowest heart rate occurring during this period was recorded as the baseline heart rate. Heart rate measures were then continued during the slide presentation. The lowest heart rate occurring during the 6-sec presentation of each slide was recorded as the heart rate for that slide.

After viewing the slides, the subjects in the delay groups were instructed that during their second session, they would complete two questionnaires measuring their affective response to the slides; they were then dismissed. The subjects in the immediate-test group stayed and completed the memory test. All subjects completed a brief questionnaire (10-15 $\mathrm{min}$ ) prior to the memory test and were then given the recognition test, administered by computer. The question and four choices were presented on the screen and remained in view until the subject entered his/her answer, at which time the next question appeared. Immediately following the recognition test was a debriefing session in which the experimenter explained the hypotheses of the experiment.

\section{EXPERIMENT 2}

As we will see in a moment, the results of Experiment 1 were complex, and, therefore, a replication seemed warranted. In addition, because the results of Experiment 1 indicated no contrast between 1- and 2-week testing, we eliminated the cumbersome 2 -week retention interval in Experiment 2 and turned to a new issue: We mentioned earlier that some studies in the literature have examined retention interval's role via within-subject comparisons, testing the same subjects both immediately after viewing the to-be-remembered material and after a delay. One might wonder, however, whether the repeated testing itself influences memory performance. To pursue this question, we tested half of the subjects in Experiment 2 immediately after they had viewed the slides, and then we retested them 1 week later. We tested the remaining subjects for the first time at a 1-week delay. This allowed comparison between subjects tested for the first time after 1 week and those tested for the second time after the same delay.

\section{Method}

Subjects. Forty undergraduates initially participated in the experiment. Three ( 2 in the arousal/repeated test group and 1 in the neutral/repeated test group) did not return for their second experimental session, and so 3 additional subjects were recruited. (Data from the 3 nonreturning subjects are included in our heart-rate analyses, and in our assessment of immediate memory performance. This is reflected in the degrees of freedom for the relevant comparisons.) The subjects were not paid; however, for participation, the subjects were entered in a lottery for $\$ 50$. The subjects were randomly assigned to the four experimental groups (arousal story vs. neutral; single test after 1 woek vs. initial test immodiately, retest after 1 week). 
Materials, Apparatus, and Design. The stimuli and apparatus were identical to those used in Experiment 1. The experiment employed a $2 \times 3 \times 4 \times 3$ design, with variables of story (arousal vs. neutral), phase of the slide material, type of information, and test schedule. Story, phase, and type of information were all as described in Experiment 1. Note that the fourth factor, test schedule, has a peculiar status, with one within-subject comparison (immediate testing vs. retesting at 1 week) and one between-subject comparison (immediate testing vs. testing for the first time after 1 week). For analysis, these comparisons were kept separate and addressed in independent analyses of variance (ANOVAs).

Procedure. The procedure was the same as that used in Experiment 1 , except for the following changes. The subjects in the singletest group were dismissed immediately after the slide sequence. For the subjects in the repeated-test group, the presentation of the slides was followed by a brief description of the memory test. The test was then administered, ending the first session's procedure. All subjects were instructed to refrain from discussing the experiment with other possible subjects.

All subjects were told to return 1 week later. Single-test subjects expected at that time to see another series of slides, then complete a questionnaire assessing their reactions to the material. Repeatedtest subjects expected a procedure identical to the first, but with new slide material. In the second session, all subjects were given the memory test for the slide material-the first presentation of these test materials for single-test subjects, and the second presentation for repeated-test subjects.

In addition, we were concerned about the computer administration of the memory test, employed in Experiment 1. Given the length of the memory test (119 items), we feared that the subjects might grow weary of the test, cease taking it seriously, and so give us a poor estimate of what they remembered. To avoid this problem, we used an interview procedure in Experiment 2, in place of the computer-administered memory test. The test items and the response alternatives were read to the subjects by the experimenter; the subjects' responses were given vocally and recorded by the experimenter. This procedure obviously risks bias from experimenter demand, but, as we will see, the results provide no indication that such bias occurred.

\section{RESULTS}

\section{Heart Rate Data}

Baseline heart rates ranged from 49 to 118 beats per minute (bpm) in Experiment 1, and from 49 to $88 \mathrm{bpm}$ in Experiment 2. Baseline heart rates of neutral and arousal subjects were quite similar-within $1.4 \mathrm{bpm}(71.9$ vs. $70.5 \mathrm{bpm}$ in Experiment 1; 68.0 vs. $68.9 \mathrm{bpm}$ in Experiment 2). In neither experiment was there a reliable difference in baseline rates between the groups (both $t s<.60)$.

During the slide presentation, heart rate was recorded during each slide. The lowest rates per slide were then averaged for each subject, to yield values for each of the phases of the slide presentation. A $2 \times 3$ (story $\times$ phase) ANOVA on these data shows no main effect of story in either procedure ( $F s<1$, for the two experiments). In both experiments, heart rates showed a decline across the three phases $\left[F(2,140)=3.740, M S_{\mathrm{e}}=4.492, p<.03\right.$, and $\left.F(2,76)=9.322, M S_{c}=4.477, p<.001\right]$.

Critically, though, there was a reliable interaction between story and phase in both of the experiments $[F(2,140)$ $=7.217, M S_{\mathrm{e}}=4.055, p<.001 ;$ and $F(2,76)=4.025$, $\left.M S_{c}=4.166, p<.05\right]$. As can be seen in Figure 1 , the
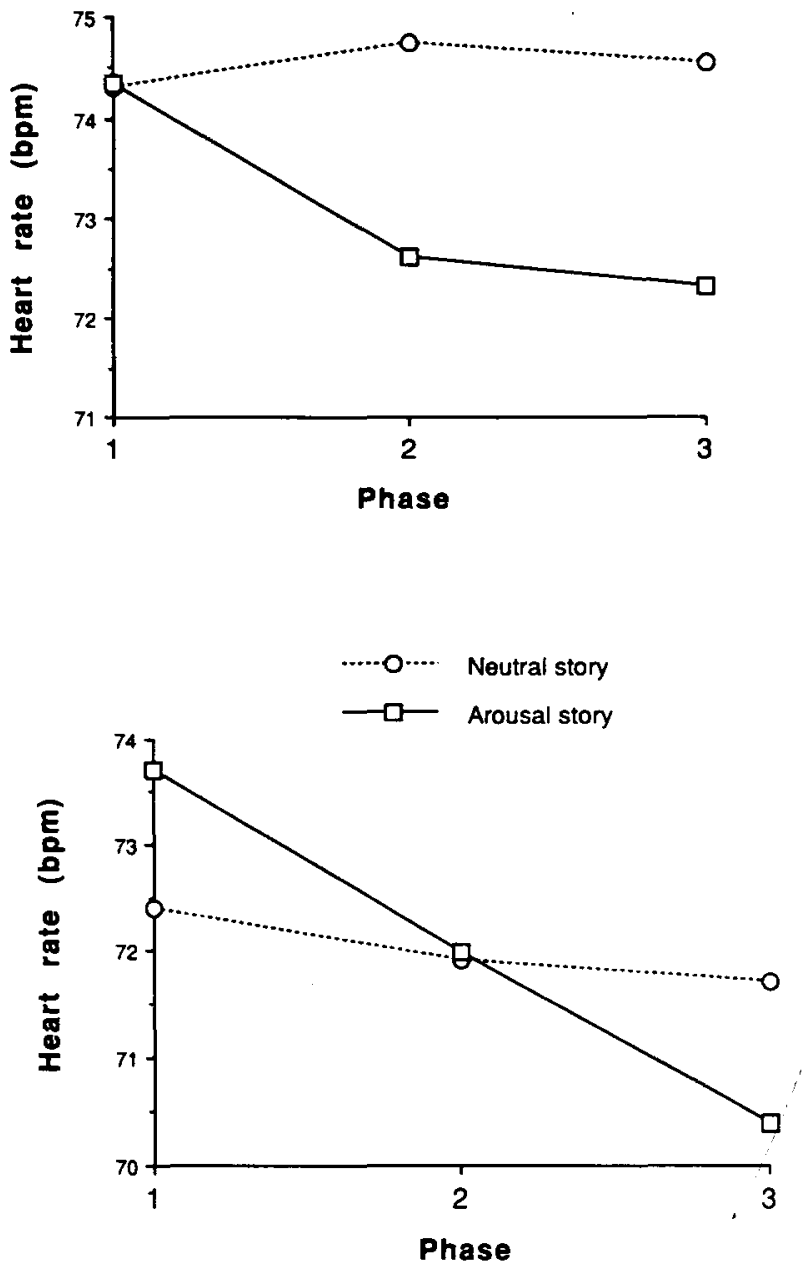

Figure 1. Heart rate data, by story type and by phase of presentation. The top panel shows the results of Experiment 1; the bottom panel shows the results of Experiment 2.

subjects who viewed the arousing slides showed a pronounced decrease in heart rate starting in the middle phase of the slides, while neutral subjects' heart rates remained relatively flat. Post hoc comparisons confirmed that neutral subjects showed no effect of phase in either study (both $F \mathrm{~s}<1$ ), whereas arousal subjects showed an effect of phase in both studies $\left[F(2,70)=9.630, M S_{\mathrm{e}}=4.493\right.$, and $F(2,38)=11.899, M S_{\mathrm{c}}=3.318$, both $\left.p s<.001\right]$.

We urge caution, however, in reading Figure 1, since the figure is potentially misleading in one regard. The figure implies a difference between groups in Experiment 2, Phase 1; if reliable, this would imply a premanipulation difference between the groups. However, this effect is nowhere close to statistically reliable. The only reliable effect in the heart rate data is the heart rate decrease in the arousal group, and this result requires a word of explanation.

These arousal data replicate Heuer and Reisberg's (1990) findings - that is, the arousal group showed a deceleration in heart rate, not the heart rate acceleration one 
associates with a defensive reaction toward noxious stimuli. However, the literature identifies two distinct heart rate patterns that characterize arousal. In addition to the acceleration pattern, Lacey and Lacey (1974) argued that some stimulation evokes an orienting response, which, in turn, is linked to a feedback mechanism through which cardiac deceleration increases cortical arousal. Likewise, Bohlin and Graham (1977) argued that heart rate deceleration occurs with the specific type of arousal associated with an orienting response (see also Graham, 1979, pp. 137-167). We note in passing that this heart rate deceleration is not unique to our stimuli, but also appeared in other procedures designed to test the Easterbrook claim (e.g., Christianson, 1984). We note in addition that the animal studies cited in support of the Easterbrook claim also presumably involve this "orienting" type of arousal, inasmuch as the arousal stimulus in these studies is typically food for food-deprived animals.

\section{One-Week Versus Two-Week Testing}

Experiment 1 allowed a comparison between subjects tested for the first time after a 1 -week delay and subjects tested for the first time after a 2-week delay. Analyses of this contrast indicated no main effect of interval $[F(1,32)<1]$ and no interactions between interval and other variables (all $F s<2.40$, all $p s>$.137). Apparently then, for these materials, forgetting had reached its asymptote by 1 week. Therefore, in all further analyses, the 1- and 2-week groups were collapsed into one "delay" group for comparison to the immediate-test group. This carries the additional advantage of allowing side-by-side comparisons of Experiments 1 and 2, as can be seen in the next section.

\section{Memory for Gist}

Figure 2 shows subjects' performance in remembering gist, with Experiment 1 shown in the top panel and Experiment 2 in the bottom. As can be seen, there was a strong effect of interval, indicating (not surprisingly) that subjects tested immediately remembered more than did those tested 1 week or 2 weeks later $[F(1,68)=58.754$, $M S_{\mathrm{e}}=.025$, and $F(1,39)=45.205, M S_{\mathrm{e}}=.017$, both $p s<.0001]$. In addition, both studies showed an effect of phase $\left[F(2,136)=30.218, M S_{\mathrm{e}}=.015\right.$, and $F(2,78)=$ $4.835, M S_{e}=.018$, both $\left.p s<.025\right]$, with memory poorest for the story's middle phase.

Of main interest, though, are the story effects. The arousal story generally led to a memory advantage, primarily lodged in Phase 2. This emerged in Experiment 1 as a story $\times$ phase interaction $\left[F(2,136)=2.899, M S_{\mathrm{e}}=\right.$ $.015, p<.06$ ]; Experiment 2 showed a weak trend in the same direction $\left[F(2,78)=2.28, M S_{\mathrm{e}}=.018, p<\right.$ .12]. Experiment 2 also showed a trend toward a story effect $\left[F(1,39)=3.135, M S_{e}=.077, p<.09\right]$, whereas Experiment 1 did not.

Experiment 2 also yielded a reliable story $\times$ interval interaction $\left[F(1,39)=12.521, M S_{\mathrm{e}}=.017, p<.005\right]$. Tukey tests revealed that the interaction was due to the
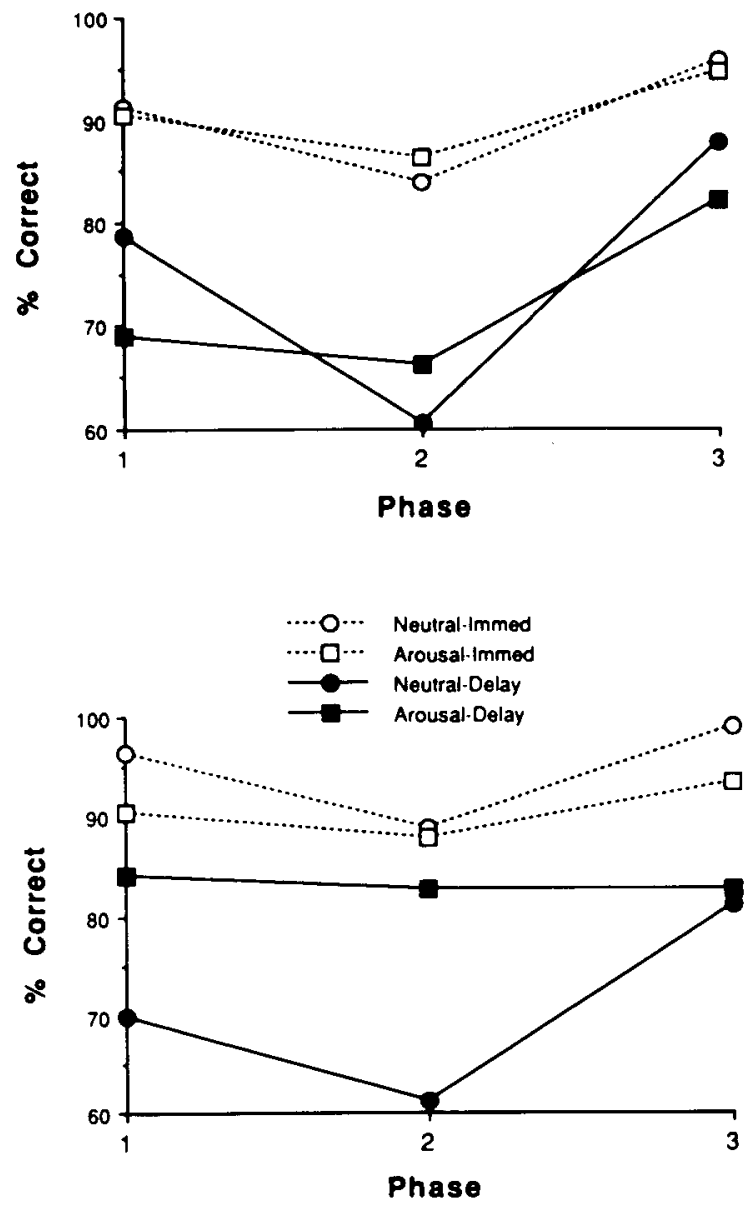

Figure 2. Memory accuracy for ald, by story type and by phase of presentation. The top panel shows the results of Experiment 1; the bottom panel shows the results of Experiment 2.

absence of a story effect in immediate testing but a reliable story effect in the delayed test.

\section{Memory for Basic-Level Visual Information}

Figure 3 shows memory results for basic-level visual information (BLVI) - that is, information that described, in basic-level terms, what each slide depicted. First, there was again a strong effect of interval, with immediate testing yielding better performance than delayed testing $[F(1,68)$ $=48.39, M S_{\mathrm{e}}=.057$, and $F(1,39)=44.31, M S_{\mathrm{e}}=.037$, both $p \mathrm{~s}<.00011$. There was also an effect of phase $\left[F(2,136)=15.738, M S_{\mathrm{e}}=.045\right.$, and $F(2,78)=3.862$, $M S_{\mathrm{e}}=.039$, both $p \mathrm{~s}<.05$ ], reflecting the fact that Phase 3 was more poorly remembered than the other phases.

The effects of story paralleled those observed with gist: Arousal improved memory, with the effect primarily visible in Phase 2. In Experiment 1, this emerged as a reliable story $\times$ phase effect $\left[F(2,136)=3.547, M S_{\mathrm{e}}=.045\right.$, $p<.05]$, with arousal subjects showing better memory for the second phase of the story material $[F(1,201)=$ 

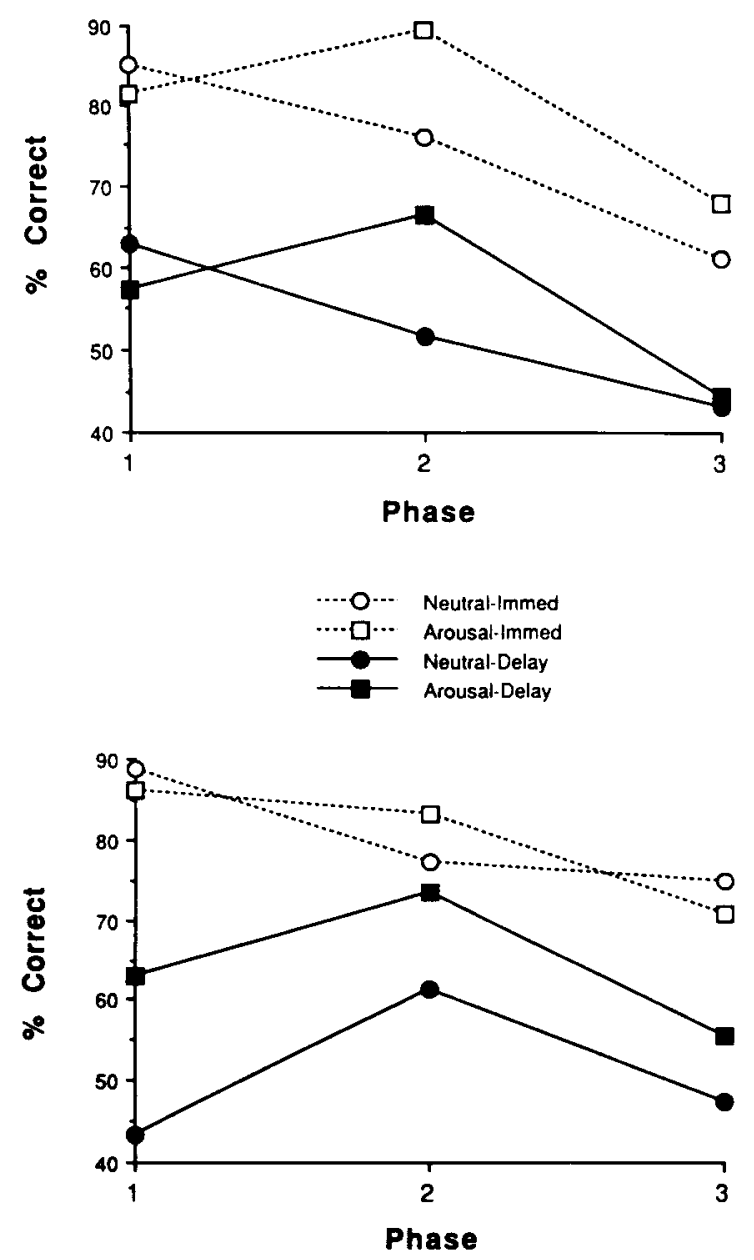

Figure 3. Memory eccuracy for basic-level visual information, by story type and by phase of presentation. The top panel shows the results of Experiment 1; the bottom panel shows the results of Experiment 2.

$\left.7.431, M S_{e}=.049, p<.01\right]$. In contrast (and continuing the parallel with gist), Experiment 2 did not show a story $\times$ phase effect, but did show a trend toward a main effect of story $\left[F(1,39)=3.56, M S_{e}=.038, p<.07\right]$. Finally, and still paralleling the results for gist, there was no story $x$ interval effect in Experiment 1, but there was a trend toward this interaction in Experiment $2[F(1,39)=$ 3.932, $\left.M S_{\mathrm{e}}=.037, p<.06\right]$.

In sum, memory for gist showed a different pattern from memory for BLVI (e.g., with regard to phase), but both were affected similarly by arousal. Arousal seemed to convey a memory advantage for both categories of information, with the effect mostly visible in the story's middle phase (i.e., where the arousal manipulation took place). In Experiment 1, this emerged as a story $\times$ phase effect for both gist and BLVI; in Experiment 2, this emerged as a trend toward a story $\times$ phase effect for gist and a main effect of story for both categories of information. The effects of story were clearly smaller with immediate testing, and, in fact, Experiment 2 yielded a reliable story $x$ interval effect for both gist and BLVI.

\section{Memory for Central Detail}

Figure 4 shows the results for memory for central detail-plot-irrelevant detail that was nonetheless spatially associated with some plot-relevant character or action. Again, we see a strong effect of interval $[F(1,68)=$ $108.82, M S_{\mathrm{e}}=.015$, and $F(1,39)=19.955, M S_{\mathrm{e}}=.027$, both ps <.0002]. In Experiment 1, there was an overall advantage for the arousal story $[F(1,68)=12.36$, $\left.M S_{\mathrm{e}}=.015, p<.001\right]$. Most striking, though, is the story $\times$ phase interaction, plainly visible in both studies $\left[F(2,136)=14.144, M S_{\mathrm{e}}=.018\right.$, and $F(2,78)=18,953$, $M S_{\mathrm{e}}=.022$, both $p$ s $\left.<.0001\right]$. Post hoc tests indicated no difference between the groups in Phase 1 of either experiment, but a strong arousal advantage in Phase 2 $\left[F(1,203)=39.727, M S_{\mathrm{e}}=.017\right.$, and $F(1,116)=$ $22.046, M S_{\mathrm{e}}=.023$, both $p$ s $<.001$ ]. In Experiment 2, the arousal subjects then had a reliable disadvantage in remembering Phase 3 of the story $[F(1,116)=11.859$, $\left.M S_{\mathrm{e}}=.023, p<.01\right]$.
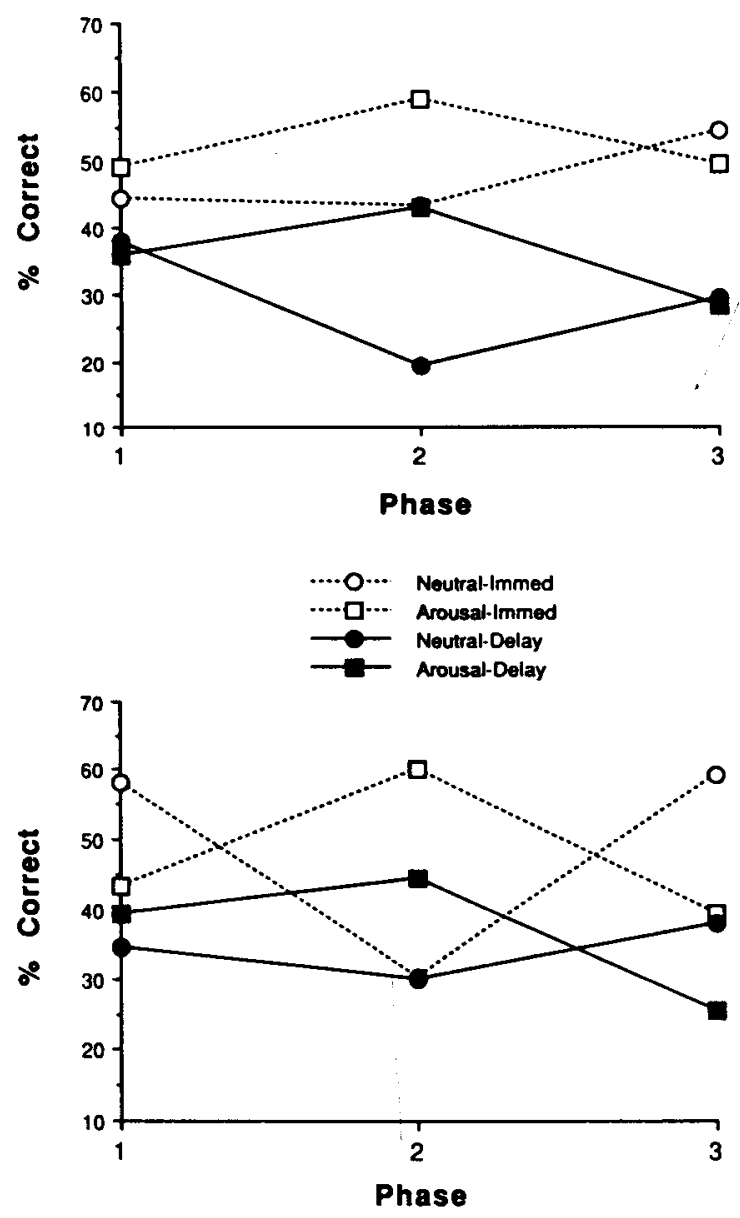

Figure 4. Memory accuracy for central detalls, by story type and by phase of presentation. Central details were defined as plotirrelevant details that were nonetheless associated with one of the story's central (plot-relevant or plot-defining) characters. The top panel shows the results of Experiment 1; the bottom panel shows the results of Experiment 2. 
The results of Experiment 2 also showed a reliable story $\times$ phase $\times$ interval interaction $\left[F(2,78)=3.912, M S_{\mathrm{e}}=\right.$ $.022, p<.05]$. This interaction reflected the fact that all story effects (the arousal advantage in Phase 2, and the arousal disadvantage in Phases 1 and 3) were more pronounced in immediate testing than they were at a delay.

\section{Memory for Background Detail}

Figure 5 shows the data for memory for background detail-plot-irrelevant detail that is spatially removed from "the action." There was a strong effect of interval $\left[F(1,68)=47.272, M S_{\mathrm{e}}=.015\right.$, and $F(1,39)=36.477$, $M S_{\mathrm{e}}=.014$, both $\left.p s<.0001\right]$; there was also a main effect of phase, with performance at its worst for the story's middle phase $\left[F(2,136)=21.674, M S_{\mathrm{e}}=.009\right.$, and $F(2,78)=8.105, M S_{e}=.010$, both $\left.p s<.001\right]$.

Both experiments also showed reliable story effects $\left[F(1,68)=5.678, M S_{\mathrm{e}}=.015\right.$, and $F(1,39)=10.821$, $M S_{\mathrm{e}}=.014$, both $p s<.05$ ], with a reliable disadvantage in performance for arousal subjects. This effect of story
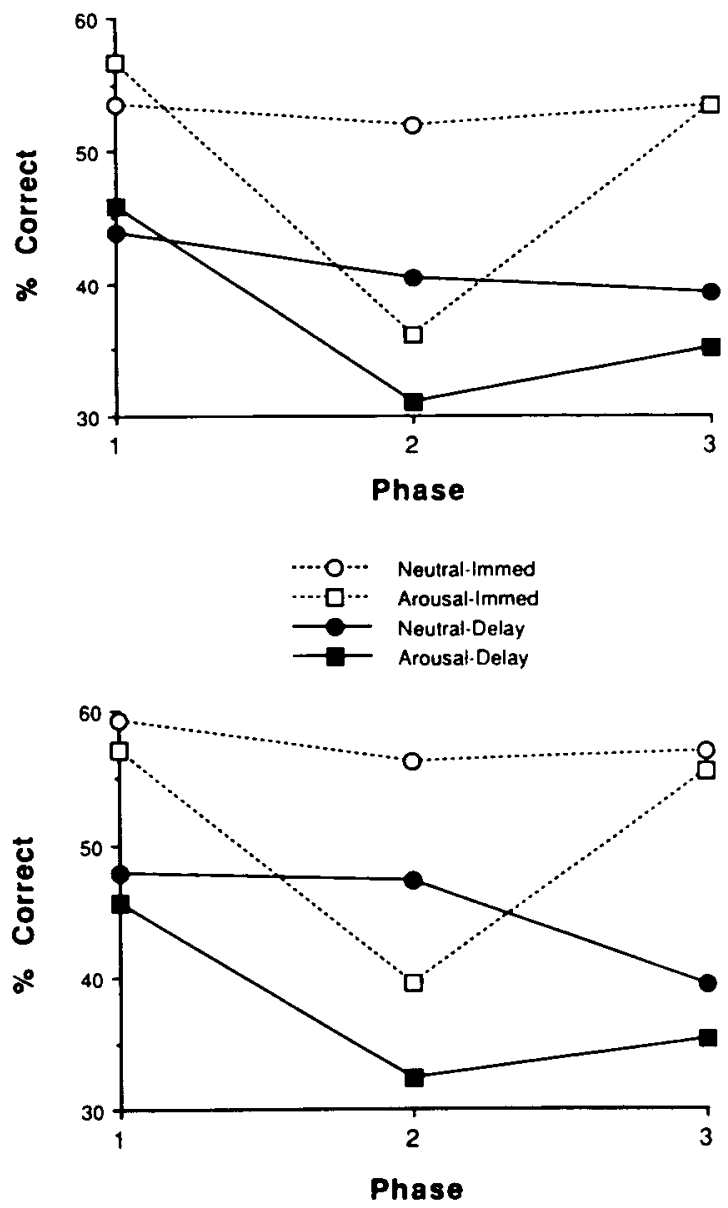

Figure 5. Memory accuracy for background detalls, by story type and by phase of presentation. Background detalls were defined as plot-irrelevant details truly in the periphery (i.e., not spatially associated with any central character). The top panel shows the results of Experiment 1; the bottom panel shows the results of Experiment 2. interacted with phase in both experiments $[F(2,136)=$ $12.64, M S_{\mathrm{e}}=.009$, and $F(2,78)=6.199, M S_{\mathrm{e}}=.010$, both $p s<.005]$; in both cases, this reflected the fact that the arousal disadvantage was most prominent in remembering Phase 2 (the locus of the arousal manipulation).

To summarize memory for detail, a story $x$ phase interaction clearly emerged for both central detail and background detail. However, for central detail, this interaction reflected a Phase 2 advantage for arousal subjects, an advantage not seen (or reversed) in the other phases. For background detail, we see the opposite pattern: a Phase 2 disadvantage for arousal subjects, with much smaller story effects in the other phases. Interactions between interval and story were inconsistent, appearing for central detail in Experiment 1 and (weakly) for background detail in Experiment 2. The pattern of this interaction, when it occurred, was generally for effects of story that were stronger in immediate testing than in delayed testing. Note that this is the reverse of the interaction observed with gist and BLVI, in which story effects tended to be weaker in immediate testing (we return to this below).

\section{Effects of Repeated Testing}

Recall that subjects tested immediately in Experiment 2 were also retested after 1 week, allowing us to examine the impact of repeated testing. The results of these comparisons are easily described: First, subjects tested for the second time after 1 week remembered considerably more than did those tested for the first time after 1 week. For gist, subjects tested for the first time after 1 week remembered $77 \%$ of the items overall; subjects retested after 1 week remembered $94 \%\left[F(1,36)=46.586, M S_{\mathrm{e}}=.018\right.$, $p<.0001]$. For BLVI, subjects tested for the first time after 1 week remembered $57 \%$ of the items tested, and subjects retested after 1 week remembered $82 \%[F(1,36)$ $\left.=48.15, M S_{\mathrm{e}}=.039, p<.001\right]$. The pattern continues for central details [ $35 \%$ vs. $48 \% ; F(1,36)=18.196, M S_{c}$ $=.027, p<.002]$, and for background details [42\% vs. $\left.54 \% ; F(1,36)=48.446, M S_{\mathrm{e}}=.009, p<.0001\right]$.

We can also compare the 1-week retest data with the results of the immediate test. (Note that this comparison is within subjects). Interestingly, we found no reliable contrasts in this comparison, for any of the four information categories. That is, the relevant ANOVAs yielded no main effects of interval (immediate vs. 1 week), and interval did not interact with any other variables. The latter result is quite striking: Apparently, the immediate test served to "lock" a memory pattern in place, so that the 1-week retest data resemble the immediate-test results far more than they resemble the 1-week first test results.

For example, in remembering gist, Experiment 2 subjects showed no story effect in the immediate testing, but a reliable story effect in the 1-week first test. The 1-week retest data show the former pattern, not the latter. As one assessment of this, an ANOVA was performed on the 1-week data, with factors of story (neutral vs. arousal), test schedule (first test vs. retest), and phase. The ANOVA yielded a story $\times$ schedule interaction $[F(1,36)=7.479$, 
$\left.M S_{c}=.018, p<.01\right]$, with an arousal effect in the singletest group but none in the retest group. The data were similar for BLVI, with a clear story $\times$ schedule effect $\left[F(1,36)=5.139, M S_{\mathrm{e}}=.039, p<.05\right]$ again reflecting the presence of a story effect in the single-test group but none in the retest group. (Note that the parallel comparisons cannot be made for central or background details: As we have already seen, these categories of information showed no contrasts between the results of immediate testing and those of the 1-week first test. Hence, for these categories, we cannot ask whether the 1-week retest shows the profile of immediate testing or of delayed testing.)

In summary, overall performance levels for the 1-week retest resembled those for immediate testing, not 1 -week first testing. When we could differentiate the patterns of immediate and 1-week first testing, the retest data show the former profile, not the latter.

\section{GENERAL DISCUSSION}

We have surveyed a complex pattern of results, so it seems appropriate to highlight the main findings. The effects of story were visible but weak for plot-relevant material (gist and BLVI), and $p$ values of .06 and .07 were common in these analyses. The effects of story were quite robust, however, in memory for details (both central and background details). To give just one example, Experiment 1 yielded a weak story $\times$ phase effect for gist $(p<$ .06 ) but a substantial story $\times$ phase effect for central detail $(p<.0001)$. Similar contrasts can be found throughout the data. Arousal clearly influenced detail memory more than it influenced memory for central materials.

Focusing on Phase 2 of the story (the phase in which the arousal manipulation took place), arousal improved memory for plot-relevant information (i.e., gist and BLVI). This arousal advantage was evident in both experiments, but it emerged in slightly different ways: In Experiment 1, the advantage was confined to Phase 2 , and so a story $x$ phase interaction was observed. The results of Experiment 2 showed a story main effect but no interaction between story and phase. (This contrast may simply reflect a difference in power between the two designs; in Experiment 1 there were almost twice as many subjects as in Experiment 2). Overall then, the data plainly show a memory advantage for the arousing materials themselves, but they are equivocal as to whether arousal has proactive or retroactive memory effects.

For central detail, both experiments showed a strong story $\times$ phase interaction, with an arousal advantage in remembering details of Phase 2. For background detail, the pattern simply reversed: Both experiments again showed a strong story $\times$ phase interaction, but this time with an arousal disadvantage in remembering Phase 2. For central detail, Experiment 1 showed a main effect of story, but this effect was almost entirely lodged in Phase 2 (see Figure 4). For background detail, both experiments showed main effects of story, but, again, this effect was mainly visible in Phase 2 (see Figure 5).
In discussing these results, we will focus on the three questions with which we began this study: What is the role of retention interval in moderating emotion's memory effects? What is the role of repeated testing? Does emotion have different effects on different categories of to-be-remembered material? We consider each of these questions in turn; the data provide clear answers for the second and third of these and tentative answers for the first. We then turn to a broader, but crucial, question. Our arousal and neutral stories obviously differ in many regards; is it possible, then, that these story differences account for the observed data pattern? Or are we justified in attributing the data to emotion?

\section{Effects of Interval}

We began this study with a conjecture that emotion's memory effects were moderated by retention interval, a conjecture fueled by several lines of evidence. The present results are consistent with the pattern in the literature, but, in the end, provide weak support for claims about retention interval's role. In Experiment 1, no reliable interactions were observed between interval and the factors of main interest here. This was true both in the comparison between 1- and 2-week testing and in the comparison between immediate and delayed testing. Experiment 2, however, did yield the predicted interactions: For both gist and BLVI, story effects were observed in delayed testing but not in immediate testing. In seeming contrast, cen-, tral detail showed a stronger effect of the story manipulation in immediate testing than it did in delayed testing. Experiment 2 yielded no story $x$ interval effects for background detail.

What should we make of this pattern? Our data indicate that retention interval's effects are not robust (consistent with the Christianson \& Loftus, 1987, nonreplication of Christianson's, 1984, results), since we have observed them in one experiment only. However, the retentioninterval effects that we did observe are consistent with a claim advanced by many authors, namely that emotion serves to retard the processes of forgetting (see Heuer \& Reisberg, in press, for a review). A number of mechanisms might produce this slowed forgetting, including "stronger" encoding of emotional events at the time they occur (e.g., Gold, 1987), or perhaps a retrieval advantage for emotional events, as other retrieval paths decay (cf. Eich \& Metcalfe, 1989). Whatever the mechanism, this proposal of retarded forgetting leads to two predictions: First, the advantages of emotion, when these occur, should increase over time. Second, the disadvantages of arousal, when these occur, should shrink over time, since an initial advantage for neutral subjects would be offset by their disadvantage for retention. This is, of course, the pattern of the story $x$ interval interactions (when these occurred) in the present results. There was one exception to this pattern in our results, but the exception is easily accommodated: In Experiment 2, with central detail, arousal subjects began with an advantage, but this advantage shrank in the 1-week test. However, the neutral subjects' per- 
formance in this immediate test was almost at chance level. Given this floor performance, there was not much for neutral subjects to forget, and so arousal subjects' performance suffered more from forgetting in this case. Thus, the gap between the groups was smaller in delayed testing.

At present, it is not clear why retention interval played a stronger role in Experiment 2 than in Experiment 1, although we are reminded here of the replication concerns that plague the "mood and memory" literature (see Blaney, 1986; Eich \& Metcalfe, 1989; Ellis \& Ashbrook, 1989). The unreliability of these results remains a problem for future study.

\section{Effects of Repeated Testing}

Unlike our tentative claims about retention interval, we can offer strong conclusions about the effects of repeated testing. After a retention interval of 1 week, the results clearly depended on whether the subject was being tested for the first time or the second. Subjects retested after a week performed better than did those tested for the first time after the same delay. However, the rehearsal not only improved performance, it also changed the pattern of performance. That is, the effects of arousal in the 1-week second test clearly resembled those in the immediate test and did not resemble those in the 1-week first test. Perhaps the rehearsal inherent in the immediate test served to freeze a memory pattern in place; perhaps subjects simply remembered their responses from the earlier test and wished to be self-consistent. In either case, this effect of repeated testing indicates a clear need for caution in interpreting studies that compare immediate and delayed tests using within-subject designs (e.g., Buckhout, Alper, Chern, Silverberg, \& Slomovits, 1974; Cutler, Penrod, \& Martens, 1987; Kebeck \& Lohaus, 1986).

\section{Effect of Category of \\ To-Be-Remembered Material}

Without question, the strongest results of the present study are those showing a complex relation between story, phase of presentation, and type of to-be-remembered material. Arousal improved memory for gist, for BLVI, and for details that happened to be associated spatially with the event's center. In contrast, arousal undermined memory for background detail.

Our story variable also interacted with phase, and this interaction was itself moderated by type of to-beremembered material. This pattern was most striking for the two categories of detail: For central detail, both experiments showed an arousal advantage in Phase 2, but not in the other phases. For background detail, we observed the opposite pattern: an arousal disadvantage in remembering background, primarily lodged in Phase 2 .

The general pattern of these results is that emotion aided memory for materials tied to the "action" in the event. This included information about the plot itself (gist and BLVI), but also included plot-irrelevant detail when that detail information was spatially and temporally linked to the arousal event (i.e., central details from the story's sec- ond phase). When the temporal link to the action was broken (as in central details from the first and third phases), memory was not improved by arousal. (Indeed, Experiment 2 showed an arousal disadvantage in remembering Phase 3's central details.) Likewise, when the spatial link to the action was broken (as in background details), arousal produced a memory disadvantage, not the advantage observed elsewhere in the study.

Why does emotion have these selective effects? We have argued elsewhere (e.g., Reisberg \& Heuer, in press) that this pattern reflects the joint action of several mechanisms. First, both the Easterbrook hypothesis and claims about "weapon focus" imply that attention is narrowed during emotional events. However, the Easterbrook claim is explicitly a claim about physiological arousal, whereas the weapon-focus effects may derive from other mechanisms-informativeness or distinctiveness of the weapon, rather than arousal (see Heuer \& Reisberg, in press). Thus, the impact of arousal may simply converge with the impact of informativeness, with both contributing (under appropriate circumstances) to a narrowing of attention. As a related point, the nature of an emotional event seems certain to shift one's "informational priorities." That is, when experiencing an emotional event, one has neither the resources nor the inclination to "enjoy the scenery." This also will serve to rivet attention on the central action, effectively leading, once again, to narrowed attention.

The mechanisms just sketched would lead to a narrowing of attention during an emotional episode, with obvious consequences for memory. In addition, we suggest that emotional events are also thought about differently from neutral events, both during the event and subsequently, and this too will contribute to the character of what is remembered. Christianson and Loftus (1991) and Heuer and Reisberg (in press) have argued that one thinks about emotional events in more "personal," more "psychological " terms, attending closely (for example) to the thoughts and feelings of the participants in the event. Correspondingly, one thinks about these events less in schematic or abstract ways. This tendency will be fueled in part by the inherent interest of emotional events, and also by the sheer distinctiveness of most emotional events. In any case, these tendencies will be revealed in the pattern of what is remembered; they can also be detected if we ask subjects directly what they thought about an emotional event (Christianson \& Loftus, 1991); they can also be detected in the pattern of intrusion errors in memory for emotional events (Heuer \& Reisberg, 1990).

\section{Story Effects Versus Emotion Effects}

In our discussion so far, we have assumed that the differences between neutral and arousal subjects can be attributed to emotion. That is, these subjects show different memory patterns because one group is remembering an emotional story and one group is remembering a neutral story. But is this justified? We designed the neutral and emotional stories to be comparable in content, in com- 
plexity, and in coherence; we also matched the content and layout of the slides as best we could. However, the fact remains that the two slide sequences and the two stories were different, and one might argue that it is these differences that lead to the memory data. For example, one might suppose that subjects have more elaborate scripts for "doctor stories" than for "mechanic stories," quite independent of emotion. Or one might suppose that subjects found it incongruous that a surgeon would allow his son to watch him at work, while no such surprise was created by the mechanic story. Again, could it be this, rather than emotion, that underlies our results?

This is an important problem for all studies of emotion's memory effects. Therefore, it seems worthwhile to dwell a moment on how this problem should be addressed. In principle, one could remove this story/arousal confound by using identical stories for the two groups and manipulating arousal in some manner external to the stories. That is, one group of subjects might watch a story after a period of exercise or while sitting next to a fearful object. We could then compare this group's performance with that of a group watching the story under more benign circumstances. This would obviously eliminate any effects of story per se. Unfortunately, though, this procedure will not serve our purposes: There is reason to believe that arousal extrinsic to the to-be-remembered materials may influence memory in a way different from emotion somehow related to the to-be-remembered material (Christianson \& Mjörndal, 1985; Christianson, Nilsson, Mjörndal, Perris, \& Tjellden, 1986). That is, "memory while emotional" may be distinct from "memory for emotional materials." Thus, to study memory for emotional materials, one needs to manipulate the to-beremembered material itself. This leaves in place the concern about story/arousal confounding.

As a consequence of this, we cannot eliminate a story confound from our studies, but we can take steps to minimize this concern. We can also design our studies to eliminate some specific suggestions for what the confound might be. For example, Dorman (1989) showed subjects a brief excerpt from a commercially produced horror movie. Subjects in the arousal group were given a summary of the film up to that point, then they saw the excerpt, accompanied by its frightening background music. Subjects in the neutral group were given a bogus summary of the film (but one that fit with the content of the excerpt) and were then shown a carefully edited version of the film. ${ }^{5}$ For the neutral subjects, the visual track was left untouched, as was the dialogue at the start of the clip. All that was changed was the soundtrack that accompanied the latter part of the clip, replacing the frightening music with some lighthearted Mozart. Subjects' memory for the film was then tested 2 weeks later.

Dorman's data are broadly consistent with the present results. In particular, Dorman found a memory advantage associated with arousal. A closer comparison of Dorman's data with the present results is not possible, since Dorman's stimulus materials will not support the fine-grained categorization scheme employed here. What is crucial for present purposes, though, is that Dorman's study involved visually identical stories. Therefore, at the least, we can eliminate accounts of the data in terms of setting, the number and appearance of the players, and so forth.

More recently, Burke (1991) showed subjects a series of slides depicting a "first date," with a man coming to a woman's apartment for dinner. The neutral and arousal versions of the story were visually identical except for one slide; arousal was manipulated thematically (via the narration) rather than visually. In the neutral version, the narration described a pleasant and unexceptional date; in the arousal version, the narration revealed the man's intentions to attack the woman. Thus, the neutral and emotional stories involved identical casts of characters and identical settings. For most of the story's duration, even the actual events depicted were identical. Even with this matching, however, Burke's data again reproduced the pattern reported here, with emotion conveying a memory advantage for gist and central details. Once again, this implies that it is emotion, not story effects, that is crucial for these effects.

Finally, other research lines have employed a different strategy in addressing the story/emotion confound by examining manipulations other than manipulations of the to-be-remembered materials. For example, Andrews (1990) tested subjects' memory for scenes selected from commercially successful movies. Subjects were identified who had seen these films 6 months or more prior to the memory study; memory was tested for several target scenes within each film. Andrews selected target scenes matched as far as possible for duration, placement within the film, and relevance to plot. Each scene, in addition, had been assessed by a panel of judges either as being bland and unemotional or as being highly emotional.

Subjects remembered the emotional scenes from these movies more accurately than they remembered the neutral scenes. Crucially for present purposes, though, subjects in this study had also filled out a separate measure, roughly assessing how "arousable" they were, at least according to self-report. This measure, developed by Mehrabian (1977a, 1977b), asks subjects how bothered they are by changes in weather, how long after a fight they remain angry, and so on. This variable interacted with the type of to-be-remembered material, such that subjects who were more arousable also had a greater memory advantage for the arousing movie scenes. This interaction between scene type and arousability implies that emotionality is indeed the key factor in distinguishing the neutral and emotional scenes. That is, one might be concerned that the emotional scenes in these movies differed in some other way from the neutral scenes-perhaps being longer or more relevant to the plot. However, these factors would not be expected to interact with the individual-difference variable.

In sum, it seems that the present memory results can be attributed to emotion and not to story effects. We reiterate, though, the need for caution on this theme. Emotional stories are different from neutral stories. The studies just 
cited used memory measures in several ways different from the measures employed in the present experiments. Further work is clearly needed on this issue, but, for the moment, the accumulation of evidence does justify speaking in terms of emotion's memory effects.

\section{The Present Results and "Weapon Focus"}

Overall then, the present data fit with other findings alleging a narrowing (or redirecting) of attention during emotional events. However, we note one regard in which our data seem to diverge from other findings in the literature: In demonstrations of the weapon-focus effect, memory is improved for the weapon and details of the hand holding the weapon; this is at the expense of memory for the face of the person wielding the weapon (Kramer, Buckhout, \& Eugenio, 1990; Loftus, Loftus, \& Messo, 1987; Maass \& Köhnken, 1989). But in our classification scheme, both of these (details of hand, details of face) would count as central details, since both are spatially and temporally associated with a central character. Therefore, within our scheme, both face and hand details should be affected similarly by emotion. Yet this is not what the weapon-focus data show.

There are several ways to address this apparent discrepancy. It may well be that the weapon-focus phenomenon simply yields a different pattern from that of emotionality. Alternatively, it may turn out that our classification scheme is not quite right: In the present study, we have distinguished between details associated with an event's central characters and those not. This categorization rests heavily on information's relevance to an episode's plot. But one could equally well distinguish between details associated with whatever was central to subjects' attention and those not. These two distinctions will often be highly correlated (i.e., one tends to pay attention to information pertinent to plot). Given this correlation, the present data, designed to explore the former distinction, can plausibly be reinterpreted as documenting the latter. On the latter view, though, there would be no disagreement between our data and the weapon-focus findings, assuming subjects' attention to be caught by the weapon and not the face of the weapon holder.

The point at issue here reaches back to a theme we mentioned earlier in this paper: If emotion has different effects on different types of material, then we need to discover the appropriate way to categorize the to-be-remembered material. The contrast between "central to plot" and "central to subjects' attention" strikes us as worth close examination in this context. However, the relevant research will take a form different from that of the present study, since provisions for tracking subjects' attention will presumably be needed (Christianson \& Loftus, 1991; Christianson, Loftus, Hoffman, \& Loftus, 1990). Alternatively, attention may be manipulated by the insertion of deliberate "attention magnets" into the to-be-remembered materials. Whichever path is taken, we view such research as crucial, given the apparent discrepancy between our results and the weapon-focus findings, and more to the point, given the huge role played in our data by type of to-be-remembered material.

\section{REFERENCES}

ANDREWS, K. (1990). The effects of emotion on memory accuracy. Unpublished bachelor's thesis, Reed College, Portland, OR.

BARTLETT, F. C. (1932). Remembering: A study in experimental and social psychology. Cambridge: Cambridge University Press.

BELBIN, E. (1950). The influence of interpolated recall upon recognition. Quarerly Joumal of Experimental Psychology, 2, 163-169.

Blaney, P. H. (1986). Affect and memory: A review. Psychological Bulletin, 99, 229-246.

Bohannon, J. N. (1988). Flashbulb memories of the space shuttle disaster: A tale of two theories. Cognition, 29, 179-196.

Bohun, G., \& Gaham, F. K. (1977). Cardiac deceleration and reflex blink facilitation. Psychophysiology, 14, 423-430.

Brown, R., KuLK, J. (1977). Flashbulb memories. Cognition, 5, 73-99.

Bruner, J. S., Matter, J., \& Papanek, M. L. (1955). Breadth of learning as a function of drive level and mechanization. Psychological Review, 42, 1-10.

Buckhout, R., Alper, A., Chern, S., Silverberg, G., SlomovITS, M. (1974). Determinants of eyewitness performance on a lineup. Bulletin of the Psychonomic Society, 4, 191-192.

BurKe, A. (1991). The effects of emotion on memory. Unpublished bachelor's thesis, Reed College, Portland, OR.

Christianson, S. - $\dot{A}$. (1984). The relationship between induced emotional arousal and amnesia. Scandinavian Joumal of Psychology, 25, 147-160.

Christianson, S.-À. (1989). Flashbulb memories: Special, but not so special. Memory \& Cognition, 17, 435-443.

Christianson, S.-A., Loftus, E. F. (1987). Memory for traumatic events. Applied Cognitive Psychology, 1, 225-239.

Christianson, S.-Á., Loftus, E. (1990). Some characteristics of people's traumatic memories. Bulletin of the Psychonomic Society, 28, 195-198.

Christianson, S.-Á., \& Loftus, E. (1991). Remembering emotional events: The fate of detailed information. Cognition \& Emotion, 5 , 81-108.

Christianson, S.-A்., Loftus, E., Hoffman, H., Loftus, G. R. (1990). Eye fixations and accuracy in detail memory of emotional versus neutral events. Joumal of Experimental Psychology: Leaming, Memory, \& Cognition, 17, 693-701.

Christianson, S.-A., Muörndal, T. (1985). Adrenalin, emotional arousal, and memory. Scandinavian Joumal of Psychology, 26, 237-248.

Christianson, S.-Ä., Nilsson, L.-G., Muörndal, T., Perris, C., - TJellden, G. (1986). Psychological versus physiological determinants of emotional arousal and its relation to laboratory induced amnesia. Scandinavian Joumal of Psychology, 27, 300-310.

Cufford, B., * Holun, C. (1981). Effects of the type of incident and the number of perpetrators on eyewitness memory. Joumal of Applied Psychology, 66, 364-370.

Cufford, B., SCotr, J. (1978). Individual and situational factors in eyewitness testimony. Joumal of Applied Psychology, 63, 352-359.

Craik, F., Blankstein, K. (1975). Psychophysiology and human memory. In P. H. Venables \& M. J. Christie (Eds.), Research in psychophysiology (pp. 389-417). London: Wiley.

Cutler, B., Penrod, S., \& Martens. T. (1987). The reliability of eyewitness identification. Law \& Human Behavior, 11, 233-258.

DEFFENBACHER, K. (1983). The influence of arousal on reliability of testimony. In S. Lloyd-Bostock \& B. Clifford (Eds.), Evaluating witness evidence (pp. 235-252). New York: Wiley.

Dorman, C. (1989). The effects of emotional arousal on memory. Unpublished bachelor's thesis, Reed College, Portland, OR.

EASTERBROOK, J. A. (1959). The effect of emotion on cue utilization and the organization of behavior. Psychological Review, 66, 183-201. Eich, E., \&ETCALFE, J. (1989). Mood dependent memory for inter- 
nal versus external events. Journal of Experimental Psychology: Learning, Memory, \& Cognition, 15, 443-455.

Ellis, H. C., Ashbrook, P. W. (1989). The "state" of mood and memory research: A selective review. Joumal of Social Behavior \& Personality, 4, 1-21.

EysEnck, M. (1976). Arousal, learning and memory. Psychological Bulletin, 83, 389-404.

EYSENCK, M. W. (1982). Attention and arousal: Cognition and performance. Berlin: Springer-Verlag.

Gold, P. (1987). Sweet memories. American Scientist, 75, 151-155.

Graham, F. K. (1979). Distinguishing among orienting, defense and startle reflexes. In H. D. Kimmel, E. H. v. Olst, \& J. G. Orlebeke (Eds.), The orienting reflex in humans (pp. 137-167). Hillsdale, NJ: Erlbaum.

Heuer, F., \& Reisberg, D. (1990). Vivid memories of emotional events: The accuracy of remembered minutiae. Memory \& Cognition, 18, 496-506.

Heuer, F., \& Reisberg, D. (in press). Emotion, arousal and memory for detail. In S.-A. Christianson (Ed.), Handbook of emotion and memory. Hillsdale, NJ: Erlbaum.

HoCKEY, G. (1978). Arousal and stress in human memory: Some methodological and theoretical considerations. In M. Gruneberg, P. Morris, \& R. Sykes (Eds.), Practical aspects of memory (pp. 295-302). New York: Academic Press.

KEBECK, G., L Lohaus, A. (1986). Effect of emotional arousal on free recall of complex material. Perceptual \& Motor Skills, 63, 461-462.

Kleinsmith, L., Kaplan, S. (1963). Paired-associate learning as a function of arousal and interpolated interval. Journal of Experimental Psychology, 65, 190-193.

KLEINSMITH, L. J., KAPLAN, S. (1964). The interaction of arousal and recall interval in nonsense syllable paired-associate learning. Journal of Experimental Psychology, 67, 124-126.

Kramer, T., Buckhout, R., \& Eugenio, P. (1990). Weapon focus, arousal and eyewitness memory: Attention must be paid. Law \& $\mathrm{Hu}$ man Behavior, 14, 167-184.

LACEY, J., \& LACEY, B. (1974). On heart rate responses and behavior: A reply to Elliott. Journal of Personality \& Social Psychology, 30, 1-18.

LiNTon, M. (1975). Memory for real-world events. In D. A. Norman \& D. E. Rumelhart (Eds.), Explorations in cognition (pp. 376-404). San Francisco: W. H. Freeman.

LofTus, E. F. (1979). Eyewitness testimony. Cambridge, MA: Harvard University Press.

LofTUS, E., \& BURNS, T. (1982). Mental shock can reproduce retrograde amnesia. Memory \& Cognition, 10, 318-323.

LofTus, E., Lofius, G., MEsso, J. (1987). Some facts about "weapon focus." Law \& Human Behavior, 11, 55-62.

MAASS, A., \& KöHNKEN, G. (1989). Eyewitness identification. Law \& Human Behavior, 13, 397-408.

Mandler, G. (1975). Mind and emotion. New York: Wiley.

MCCloskey, M. WiBle, C. G., \& Cohen, N. J. (1988). Is there a special flashbulb-memory mechanism? Journal of Experimental Psychology: General, 117, 171-181.

Merrabian, A. (1977a). Individual differences in stimulus screening and arousability. Joumal of Personality, 45, 237-250.

Mehrabian. A. (1977b). A questionnaire measure of individual differences in stimulus screening and associated differences in arousability. Environmental Psychology \& Non-Verbal Behavior, 1, 89-103.

MoRRIS, M., \& MURPHY, G. (1990). Converging operations on a basic level in event taxonomies. Memory \& Cognition, 18, 407-418.
NeISSER, U. (1982). Memory observed. San Francisco: W. H. Freeman. Neisser, U., Harsch, N. (1990, February). Phantom flashbulbs: False recollections of hearing the news about Challenger. Paper presented at the Conference on Affect and Flashbulb Memories, Emory University, Atlanta, GA.

Pillemer, D. B. (1984). Flashbulb memories of the assassination attempt on President Reagan. Cognition, 16, 63-80.

REISBERG, D., Heuer, F. (in press). Remembering emotional events. In E. Winograd \& U. Neisser (Eds.), Affect and flashbulb memories. New York: Cambridge University Press.

Reisberg, D. Heuer, F., Mclean, J., \& O'Shaughnessy, M. (1988). The quantity, not the quality, of affect predicts memory vividness. Bulletin of the Psychonomic Society, 26, 100-103.

RifKIN, A. (1985). Evidence for a basic level in event taxonomies. Memory \& Cognition, 13, 538-556.

Rosch, E. H. (1978). Principles of categorization. In E. Rosch \& B. B. Lloyd (Eds.), Cognition and categorization (pp. 27-48). Hillsdale, NJ: Erlbaum.

Rubin, D. C., Kozin, M. (1984). Vivid memories. Cognition, 16, 81-95.

SIEGEL, J., LoFTUS, E. (1978). Impact of anxiety and life stress upon eyewitness testimony. Bulletin of the Psychonomic Society, 12, 479-480.

SNYDER, N. (1989). What does emotion do to memory? Unpublished bachelor's thesis, Reed College, Portland, OR.

VALLACHER, R., \& WEGNER, D. (1987). What do people think they're doing? Action identification and human behavior. Psychological Review, 94, 3-15.

WagenaAr, W. A., \& Groeneweg, J. (1990). The memory of concentration camp survivors. Applied Cognitive Psychology, 4, 77-88.

White, R. T. (1989). Recall of autobiographical events. Applied Cognitive Psychology, 3, 127-136.

\section{NOTES}

1. In describing these studies, it is unclear whether one should speak of arousal's effects on memory or emotion's effects. Relatively few studies, for example, address the question of how arousal shapes memory in the absence of emotion. Likewise, emotion's memory effects may be attributable to arousal, but they also may be attributable to some other concomitant of emotion. In describing the evidence, therefore, we will use the term emotion to refer to a "package" of factors (including arousal itself) that may lie behind the observed effects. However, in describing several studies in the literature, we adopt a more cautious stance, and we will speak of arousal effects, simply because it is arousal that was overtly manipulated in these studies and arousal that was explicitly monitored (e.g., via heart rate).

2. The Heuer and Reisberg study, just described, was modeled after this earlier procedure.

3. The experiment reported as Experiment 1 was actually completed after that reported as Experiment 2; we have reversed the sequence for expository ease.

4. In an initial analysis, we ascertained that there were no detectable differences between the subjects from these two campuses; hence, the two populations were merged in the analyses reported here.

5. This film had been developed for an earlier study by Burke and Wessler (1990. [Memory and emotion]. Unpublished data.)

(Manuscript received September 28, 1990; revision accepted for publication August 5, 1991.) 